\title{
Giant cardiac tumours in the newborn: an unusual image
}

\author{
J. Kwiatkowska ${ }^{1}$, S. Ciemny ${ }^{1}$, D. Kozłowski ${ }^{2}$ \\ ${ }^{1}$ Department of Paediatric Cardiology and Congenital Heart Defects, Medical University of Gdansk, Poland \\ ${ }^{2}$ Department of Cardiology and Electrotherapy, Medical University of Gdansk, Poland
}

[Received: 20 June 2017; Accepted: 15 December 2017]

Primary heart tumours in the paediatric population are very rare and they range from $0.01 \%$ to $0.04 \%$. Most are benign lesions of which about half are rhabdomyomas. Rhabdomyoma tumour diagnosis is associated with a $75-80 \%$ risk of tuberous sclerosis complex (TSC). TSC are characterised with numerous changes of hamartoma-type located in the brain, kidneys, skin and other organs including the heart. More than two-thirds of newborns with TSC present rhabdomyomas in the heart. These changes may be asymptomatic, but in some cases they may cause heart failure, arrhythmias and death. We present a case report of an infant with giant rhabdomyoma tumours in the course of TSC. (Folia Morphol 2018; 77, 3: 601-603)

Key words: cardiac tumour, rhabdomyoma of heart, primary heart tumours in children, tuberous sclerosis complex, giant heart tumours

\section{INTRODUCTION}

Primary cardiac tumours in the paediatric population are very rare and occur with a frequency from $0.01 \%$ to $0.04 \%[3,10]$. The overwhelming majority are benign and $45-58 \%$ of heart tumours in children are rhabdomyoma $[1,7]$. Less common tumours in children are fibroma, angioma and teratoma [1]. Myxoma, the most common primary cardiac tumour in adults, is very rare in the paediatric population. The diagnosis of rhabdomyoma in a child is associated with $75-80 \%$ risk of tuberous sclerosis $[2,14]$. Tuberous sclerosis complex (TSC) is a genetic disease first described by Bourneville, a French neurologist, in 1880. TSC is caused by mutations in the TSC1 gene (chromosome 9th) which code for Hamartin or TSC2 gene (chromosome 16th) which code for Tuberine. It is characterised with numerous changes of hamartoma-type located in the brain, kidneys, skin and other organs and manifests itself with characteristic symptoms such as epilepsy, mental retardation, and skin lesions. Over two-thirds of infants with TSC pre- sent rhabdomyoma in the heart [4]. Rhabdomyoma tumour is a major feature in the diagnosis of TSC [9]. Macroscopically, these are uniform, round tumours with a lighter shade than a healthy cardiac muscle. The microscopically pathogenic feature of rhabdomyoma is the presence of spider cells with centrally placed cytoplasm containing the nucleus and myofibrils radiating to the cell wall. Rhabdomyomas exhibit immunoreactivity with the muscle markers desmin, actin, myoglobin, vimentin, hamartin and tuberin. Immunohistochemical studies showed that the spider cells exhibit immunoreactivity with ubiquitin [15]. The changes are localised in $94 \%$ in the ventricles and may be clinically asymptomatic; however, in some cases they can lead to a heart failure, arrhythmias and death $[6,11]$. Rhabdomyoma is a benign tumour, with no tendency to infiltrate neighbouring structures. The possible location of the tumour is a cardiac conduction system, where by pressure on neighbouring tissues, the tumour may manifest clinically as a conduction block and lead to death [12].

Address for correspondence: Dr. S. Ciemny, Department of Paediatric Cardiology and Congenital Heart Defects, Medical University of Gdansk, ul. Dębinki 7, 80-211 Gdańsk, Poland, tel: +48 5834928 70, e-mail: s_e.b_a@gumed.edu.pl 


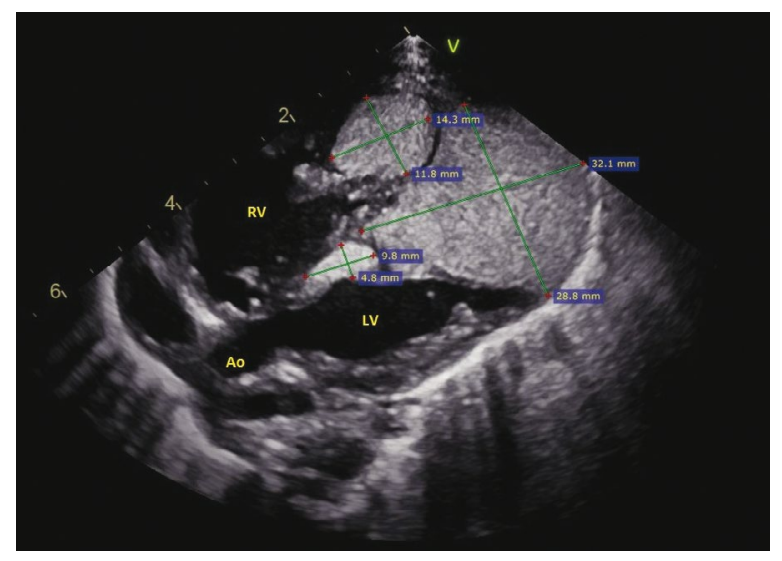

Figure 1. Modified 5-chamber view; Ao — aorta; LV — left ventricle; RV — right ventricle.

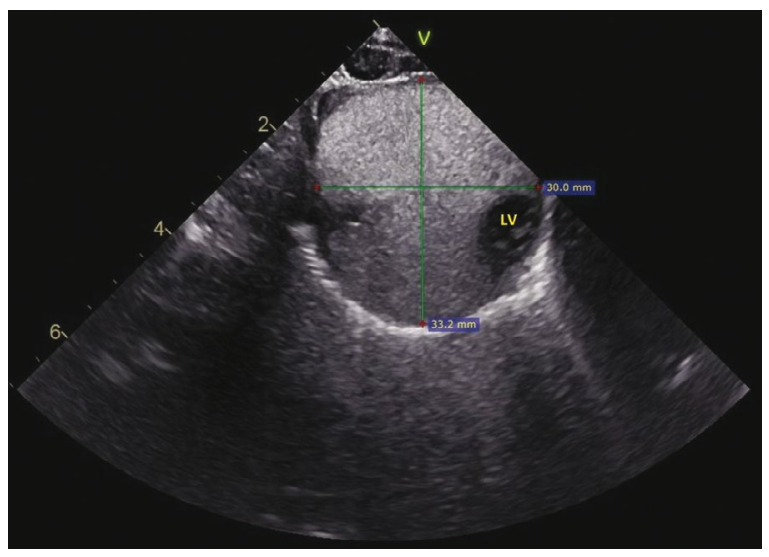

Figure 2. Parasternal short axis view; LV — left ventricle.

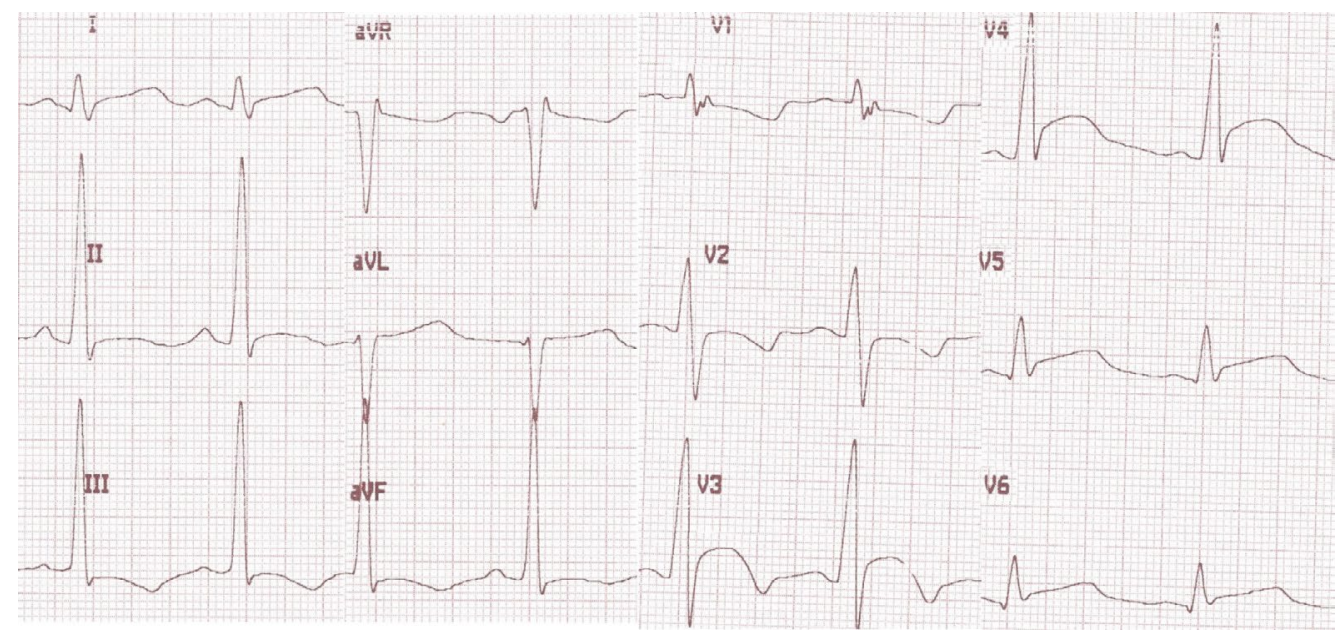

Figure 3. Regular sinus rhythm 143/min. Normal axis deviation. Normal SA and AV conduction. QRS $70 \mathrm{~ms}$, no signs of intraventricular conduction disturbances. In lead V1 Rsr' QRS morphology. No signs of atrial or ventricular hypertrophy. ST segment depression $>1 \mathrm{~mm}$ and T wave changes: positive/negative in leads II, III, aVF and V1-V3. In leads V3-V6 positive J point deflection (1-3 mm) with evident domed ST-segment elevation. OT $260 \mathrm{~ms}$ (not corrected).

A characteristic feature of rhabdomyoma is a tendency to involution and a total regression of changes until 2 years of age is observed in $75-80 \%$ of affected children [5]. However, cardiological disorders are one of the leading causes of death in patients with TSC in the first decade of life. In symptomatic patients, the treatment option is a cardiac surgery; however, there is a high risk of mortality [5]. Over recent years, more than dozen case reports of tumour regression after the application of the mTOR inhibitor Everolimus have been published $[8,13]$.

We present a case of a child with giant heart tumours (rhabdomyoma) in the course of TSC. According to the best of our knowledge, these are one of the largest tumours described in the literature.

\section{CASE REPORT}

The newborn with prenatally diagnosed (ultrasonography and magnetic resonance imaging exams) multiple tumours of the heart and brain lesions characteristic of TSC underwent a cardiologic consultation immediately after the birth. The neonate was clinically asymptomatic.

Echocardiography revealed normal ejection fraction and left ventricular size (LVIDd $17 \mathrm{~mm}$ ) and confirmed the presence of multiple cardiac tumours, the largest in the apex of the dimensions of $33 \times 30 \mathrm{~mm}$, two smaller in the interventricular septum with dimensions of $14 \times 11 \mathrm{~mm}$ and $9 \times 5 \mathrm{~mm}$ and a few small ones in the free wall of right and left ventricle (Figs. 1, 2). There was no evidence of obstruction of both the inflow and the outflow track of the heart. 


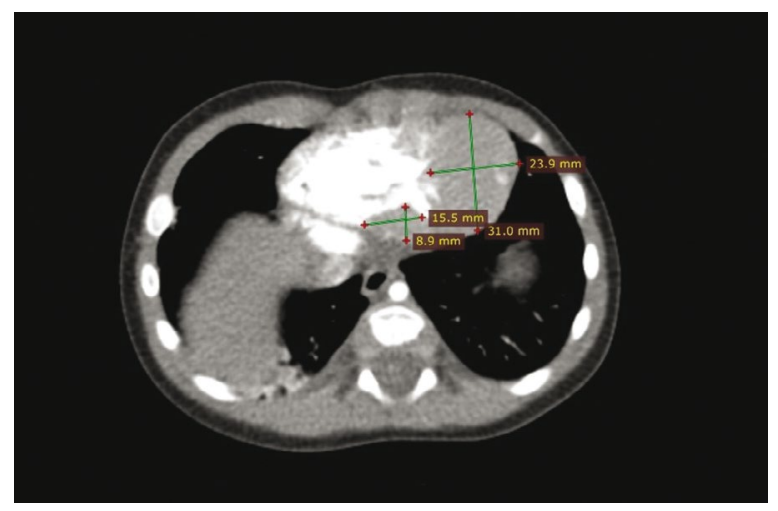

Figure 4. Computed tomography angiography of the chest.

The right ventricle pressure was increased up to $70 \mathrm{mmHg}$, measured from the tricuspid regurgitation.

Several electrocardiogram (ECG) examinations showed generalised repolarisation abnormalities (Fig. 3). There were no arrhythmias on the $24 \mathrm{~h}$ Holter-ECG monitoring and on telemonitoring. The laboratory tests revealed normal level of B-type natriuretic peptide and the troponin level increased up to $22 \times$ upper limit of hospital laboratory reference range for adults. Because of the normal global ejection fraction and the lack of therapeutic options at that time, the coronary angiography was not performed. The normalisation of levels of troponin at 8 weeks of age was documented.

During the 3 months of follow-up the elevated pressure in the right ventricle was present in echocardiographic exams. Because of this, the chest angiocomputed tomography was performed (Fig. 4) and it showed no obstructions in the runoff from the pulmonary veins to the left atrium. In the subsequent echocardiographic studies the normalisation of the pressure in the right ventricle was observed. During half year of the follow-up, the child remained asymptomatic.

\section{CONCLUSIONS}

An asymptomatic neonate with multiple huge cardiac tumours requires a close follow-up with serial imaging and electrocardiography because of the risk of a sudden and unsuspected death in this group of patients. A spontaneous resolution of the rhabdomyomas may occur in children with the confirmed diagnosis of tuberous sclerosis.

\section{REFERENCES}

1. Becker AE. Primary heart tumors in the pediatric age group: a review of salient pathologic features relevant for clinicians. Pediatr Cardiol. 2000; 21(4): 317-323, doi: 10.1007/ s002460010071, indexed in Pubmed: 10865004.

2. Beghetti M, Gow RM, Haney I, et al. Pediatric primary benign cardiac tumors: a 15-year review. Am Heart J. 1997; 134(6): 1107-1114, indexed in Pubmed:9424072.

3. Freedom RM, Lee KJ, MacDonald C, et al. Selected aspects of cardiac tumors in infancy and childhood. Pediatr Cardiol. 2000; 21(4): 299-316, doi:10.1007/s002460010070, indexed in Pubmed: 10865003.

4. Gibbs JL. The heart and tuberous sclerosis. An echocardiographic and electrocardiographic study. Br Heart J. 1985; 54(6): 596-599, indexed in Pubmed: 4074592.

5. Hinton RB, Prakash A, Romp RL, et al. Cardiovascular manifestations of tuberous sclerosis complex and summary of the revised diagnostic criteria and surveillance and management recommendations from the International Tuberous Sclerosis Consensus Group. J Am Heart Assoc. 2014; 3(6): e001493, doi: 10.1161/JAHA.114.001493, indexed in Pubmed: 25424575.

6. Kwiatkowska J, Wałdoch A, Meyer-Szary J, et al. Cardiac tumors in children: A 20-year review of clinical presentation, diagnostics and treatment. Adv Clin Exp Med. 2017; 26(2): 319-326, indexed in Pubmed: 28791852.

7. Linnemeier $L$, Benneyworth $B D$, Turrentine $M$, et al. Pediatric cardiac tumors: a 45-year, single-institution review. World J Pediatr Congenit Heart Surg. 2015; 6(2): 215-219, doi: 10.1177/2150135114563938, indexed in Pubmed: 25870340.

8. Mlczoch E, Hanslik A, Luckner D, et al. Prenatal diagnosis of giant cardiac rhabdomyoma in tuberous sclerosis complex: a new therapeutic option with everolimus. Ultrasound Obstet Gynecol. 2015; 45(5): 618-621, doi: 10.1002/ uog.13434, indexed in Pubmed: 24913039.

9. Northrup $H$, Krueger DA. Tuberous sclerosis complex diagnostic criteria update: recommendations of the 2012 linternational Tuberous Sclerosis Complex Consensus Conference. Pediatr Neurol. 2013; 49(4): 243-254, doi: 10.1016/j.pediatrneurol.2013.08.001, indexed in Pubmed: 24053982.

10. Reynen K. Frequency of primary tumors of the heart. Am J Cardiol. 1996; 77(1): 107, doi: 10.1016/s00029149(97)89149-7.

11. Sciacca P, Giacchi V, Mattia C, et al. Rhabdomyomas and tuberous sclerosis complex: our experience in 33 cases. BMC Cardiovasc Disord. 2014; 14: 66, doi: 10.1186/14712261-14-66, indexed in Pubmed: 24884933.

12. Song Y, Yao Q, Liu C, et al. Morphological observations of tumors in cardiac conduction system. J Geriatric Cardiol September. 2007; 4: 164-167.

13. Tiberio D, Franz DN, Phillips JR. Regression of a cardiac rhabdomyoma in a patient receiving everolimus. Pediatrics. 2011; 127(5): e1335-e1337, doi:10.1542/peds.20102910, indexed in Pubmed: 21464184.

14. Tworetzky W, McElhinney DB, Margossian R, et al. Association between cardiac tumors and tuberous sclerosis in the fetus and neonate. Am J Cardiol. 2003; 92(4): 487-489, indexed in Pubmed: 12914889.

15. Uzun O, Wilson DG, Vujanic GM, et al. Cardiac tumours in children. Orphanet J Rare Dis. 2007; 2: 11, doi: 10.1186/17501172-2-11, indexed in Pubmed:17331235. 